\title{
Application of Neural Network in Atmos- pheric Refractivity Profile at Makurdi
}

\author{
Agbo G.A, Ibeh G. F, Onah D.U, Umahi A.E, Nnaji E \& Ugwuonah F.C \\ Industrial Physics Department, Ebonyi State University, Abakaliki, Ebonyi State \\ E-mail: ibehgabriel@ymail.com, ibehgabrielfriday@gmail.com
}

\begin{abstract}
The refractivity profile variation in troposphere is one of the aspects that influences long-distance terrestrial electromagnetic wave propagation and performance of communication systems. This study is aimed at calculating and estimating radio refractivity at Makurdi with tropospheric parameters of relative humidity, absolute temperature and atmospheric pressure using ITU-R and artificial neural network models. Validation results are thus, absolute temperature $=$ $0.4313 \mathrm{~K}$, relative humidity $=0.9989 \%$, pressure $=0.0201(\mathrm{hpa})$ respectively. The validation of the correlation coefficient results shows that all the tropospheric parameters have effects on radio refractivity, but relative humidity has more effect which is attributed to the large quantity of moisture at the troposphere. From the estimation results, it is clear that artificial neural network has the capacity of estimating tropopheric refractivity since the estimated values has close agreement with the calculated values.
\end{abstract}

Keywords: refractivity, artificial neural network, tropospheric, ITU-R model

\section{Introduction}

The conditions in the troposphere have a profound effect on the propagation of radio waves. Radio-wave propagation is determined by changes in the refractive index of air in the troposphere. Changes of temperature, pressure and humidity, as well as clouds and rain, influence the way in which radio waves propagate from one point to another in the troposphere (Ibeh et al, 2012). This region exerts a considerable influence on radio waves at frequencies above $30 \mathrm{MHz}$ (Hall, 1979). Ionization of air in the troposphere is negligible since Ultraviolet radiation reaching there is negligibly small, but due to the presence of gases like oxygen and water vapour which have electric dipole moments, the troposphere has a dielectric constant and hence a refractive index (Ajayi, 1989). The refractivity at this region can either be predicted or calculated using various models. In this work, pattern recognition algorithms, such as artificial neural network (ANN) model are used in order to predict refractivity, using only the surface values of absolute temperature, pressure, and relative humidity.

\section{Materials and procedures}

\subsection{Source of data}

The meteorological data of relative humidity, temperature and pressure were obtained from Centre for atmospheric research, Anyigba-CBSS, University of Nigeria Nsukka. Equations (2) and (3) given below were used to compute the values for refractivity and water vapour pressure $(e)$.

\subsection{Theory of refractivity}


Radio -wave is determined by changes in the refractive index of air in the troposphere. Because it is close to unity (about $1.0003)$, the refractive index of air is measured by a quantity called the radio refractivity, $\mathrm{N}$ which is related to refractive index, $\mathrm{n}$ as (ITU-R, 2003):

$$
\mathrm{n}=1+\mathrm{N} \times 10^{6}
$$

In terms of measured meteorological quantities, the refractivity $\mathrm{N}$ can be expressed as:

$$
\mathrm{N}=77.6 \frac{\mathrm{p}}{T}+3.73 \times 10^{5}\left(\frac{e}{T^{2}}\right)
$$

Where: $\mathrm{p}=$ atmospheric pressure (hpa), $e=$ water vapour pressure and $\mathrm{T}=$ absolute temperature $(\mathrm{K})$.

The water vapour pressure $e$ is usually calculated from the relative humidity with the following equation:

$$
e=\frac{R H}{100} \mathrm{a} \exp \left(\frac{b t}{t+c}\right)
$$

Where the temperature is given in ${ }^{\circ} \mathrm{C}$ and the coefficients $\mathrm{a}, \mathrm{b}$ and $\mathrm{c}$ take the following values:

$\mathrm{a}=6.1121, \mathrm{~b}=17.502$, and $\mathrm{c}=240.97$. Therefore,

$$
e=\frac{R H}{100} 6.1121 \exp \left(\frac{17.502 t}{t+240.97}\right)
$$

Where: $\mathrm{RH}=$ relative humidity $(\%), \mathrm{t}=$ temperature in degree Celsius ${ }^{\circ} \mathrm{C}$.

\subsection{Procedure of artificial neural net- work estimation}

Artificial neural network (ANN) model is a computer software program that behaves the same way as the human brain. The network usually consists of an input layer, some hidden layers and an output layer (Ibeh and Agbo, 2012)
For the estimation of tropospheric refractivity, 3-2-1 multilayer peceptron (MLP) neural networks were used, which includes the input layer, a linear output layer and a sigmoid hidden function. In order to predict the tropospheric refractivity, a classifier were developed, which merely associates the ground values of pressure, absolute temperature and relative humidity and predicts the tropospheric refractivity at Makurdi for the specific observatory period. The selection of sigmoid transfer function is because it allows any relation between the system predictors and the output.

The network predictors consist of $3 \mathrm{X}$ $\mathrm{N}$ matrix, where each row represent the ground pressure, absolute temperature and relative humidity respectively for total of $\mathrm{N}$ observatory period, while each Colum stands for the days used. In order to validate the refractivity results and investigate for any further improvement and recommendation of the model, regression analyses were carried out.

\section{Results}
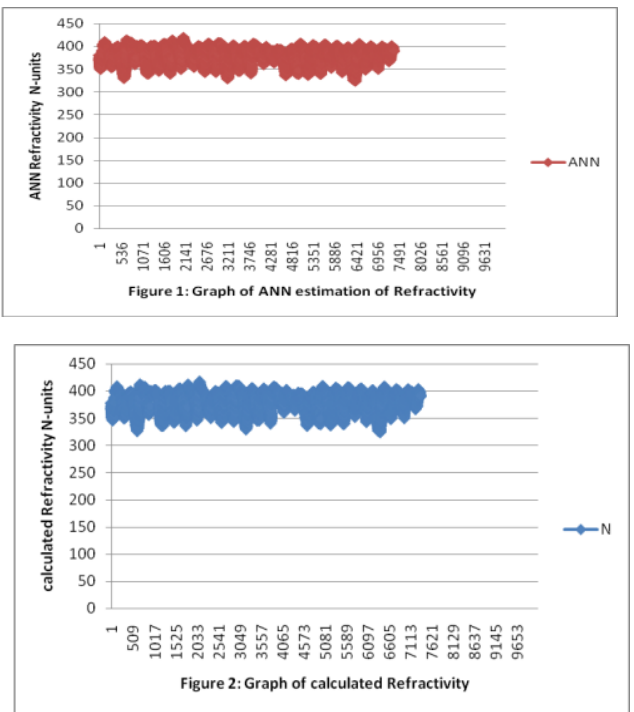


\section{Conclusion}

Validation results are thus, absolute temperature $=0.4313 \mathrm{~K}$, relative humidity $=$ $0.9989 \%$, pressure $=0.0201$ (hpa) respectively. The validation of the correlation coefficient results shows that all the tropospheric parameters have effects on radio refractivity, but relative humidity has more effect which is attributed to the large quantity of moisture at the troposphere. From the estimation results, it is clear that artificial neural network has the capacity of estimating tropopheric refractivity since the estimated values has close agreement with the calculated values.

\section{References}

[1] Ajayi G.O (1989). Physics of the tropospheric Radio propagation. Radio Africa'97, 42-72.

[2] Aysegul Y (2006). Atmosphere physics lecture notes, Canakkale Onsekiz Mart Nuiversity.
[3] Hall MPM (1979). Tropospheric effects on electromagnetically measured Range: prediction from surface weather data'. Radio sciences 6(3), 353- 367

[4] ITU-R (2003). Effect of Temporal Variations of Refraction on Radio wave Propagation, Rec P881, ITU, Geneva, 131-138.

[5] Ibeh G.F, Agbo G.A and Rabia S (2012). Application of artificial neural network and Angstrom-Prescott models in prediction of global solar radiation of Uyo City, Nigeria with atmospheric parameters. Advances in Applied Science Research, 3 (1):619624.

[6] Ibeh G.F and Agbo G.A (2012), Estimation of Tropospheric Refractivity with Artificial Neural Network at Minna, Nigeria, Global Journal of Science Frontier Research Interdiciplinary. Vol. 12, pp 8-14 